This item was submitted to Loughborough's Research Repository by the author.

Items in Figshare are protected by copyright, with all rights reserved, unless otherwise indicated.

\title{
Post-consumer waste management issues in the footwear industry
}

PLEASE CITE THE PUBLISHED VERSION

PUBLISHER

Professional Engineering Publishing / @ IMechE

VERSION

VoR (Version of Record)

LICENCE

CC BY-NC-ND 4.0

REPOSITORY RECORD

Staikos, Theodoros, and Shahin Rahimifard. 2019. "Post-consumer Waste Management Issues in the Footwear Industry”. figshare. https://hdl.handle.net/2134/5060. 
This item was submitted to Loughborough's Institutional Repository (https://dspace.lboro.ac.uk/) by the author and is made available under the following Creative Commons Licence conditions.

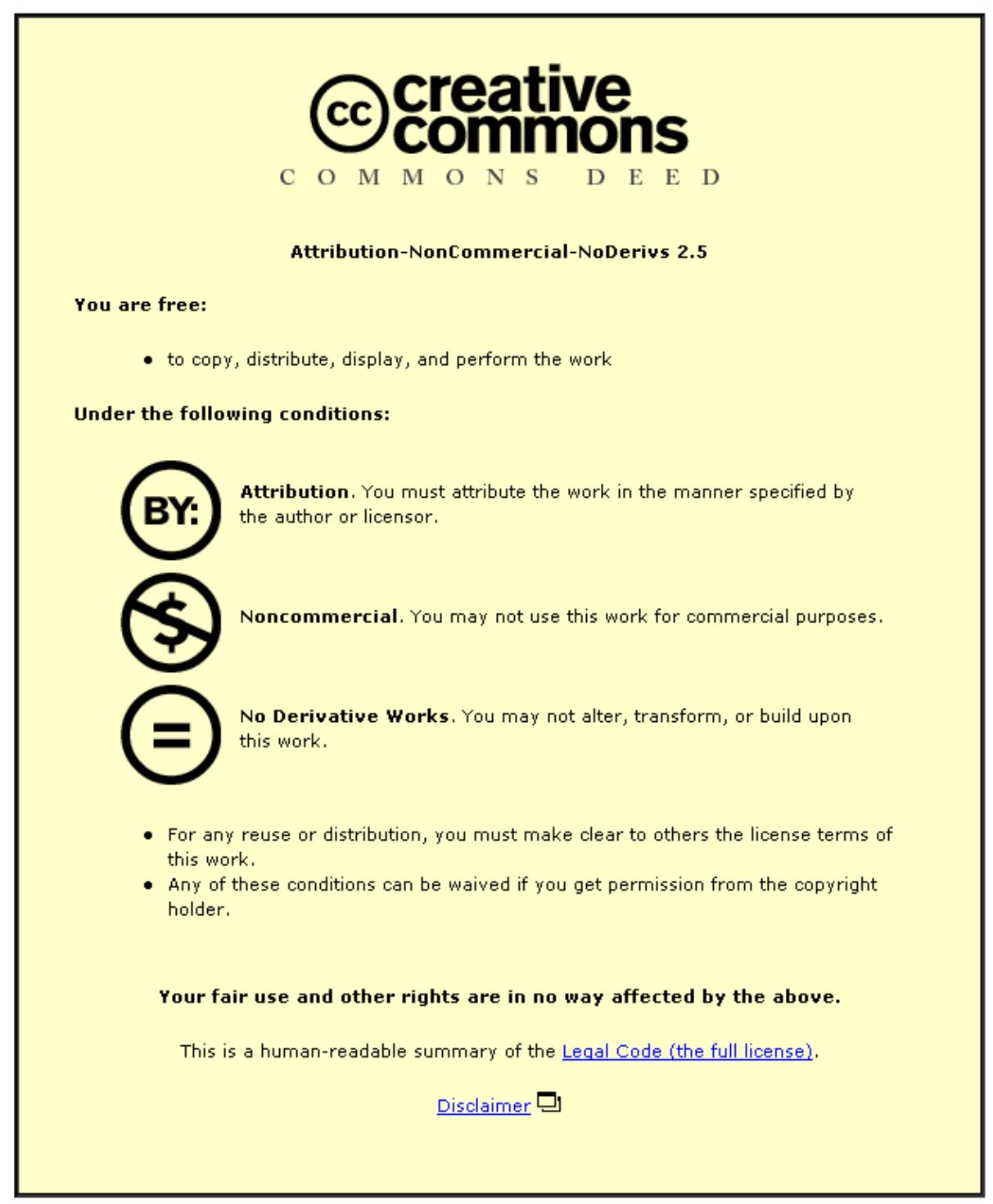

For the full text of this licence, please go to: http://creativecommons.org/licenses/by-nc-nd/2.5/ 


\title{
Post-consumer waste management issues in the footwear industry
}

\author{
T Staikos* and S Rahimifard \\ Wolfson School of Mechanical and Manufacturing Engineering, Loughborough University, Loughborough, UK \\ The manuscript was received on 11 September 2006 and was accepted after revision for publication on \\ 30 October 2006.
}

DOI: 10.1243/09544054JEM732SC

\begin{abstract}
Currently, 17 billion pairs of shoes are produced worldwide every year, and this figure continues to rise. This creates an enormous amount of post-consumer (end-of-life) shoe waste that is currently being disposed of in landfill sites around the world. The research reported in this paper is an initial investigation into realization of a holistic approach to application of recovery and recycling in the footwear industry. The paper provides a brief review of the trends in the footwear sector regarding the amount of end-of-life waste produced, together with existing reuse and recycling activities. It also presents an integrated waste management framework by combining a mix of design and material improvements, as well as reuse, recycling, and energy recovery activities, and concludes by examining the challenges in establishing end-of-life product recovery procedures for post-consumer shoes.
\end{abstract}

Keywords: end-of-life management, shoe recycling, product recovery, footwear industry

\section{INTRODUCTION}

The footwear industry over the last 20 years has placed significant effort in improving material efficiency during the production phase, as well as eliminating the use of hazardous materials in shoe production. However, the environmental gains made in production are being overtaken by the considerable increase in the demand for footwear products. Moreover, the useful life of shoes is relatively short and progressively decreasing as a result of rapid market changes and consumer fashion trends. This creates a large waste stream at the end of the functional life of shoes, which are often being disposed of in landfills. Producer responsibility and other forthcoming environmental legislation, as well as increasingly environmental consumer demands, are expected to challenge the way the footwear industry deals with its end-of-life waste. Thus, an investigation into a holistic approach to shoe recovery and recycling is being undertaken, as reported in this paper.

*Corresponding author: Wolfson School of Mechanical and Manufacturing Engineering, Loughborough University, Asby Road, Loughborough LE11 3TU, UK. email: T.Staikos@lboro. ac.uk
The initial part of the paper provides a review of current trends regarding the amount of end-of-life waste produced by the footwear industry. The latter sections present an integrated waste management framework for shoes and discuss the challenges in establishing end-of-life product recovery procedures for post-consumer shoes.

\section{SCALE OF POST-CONSUMER SHOE WASTE}

From 1990 to 2004, worldwide footwear production increased by a staggering 70 per cent to more than 17 billion pairs of shoes per year [1]. In fact, worldwide footwear production and consumption are being doubled every 20 years, from 2.5 billion pairs in 1950 to an expected 20 billion pairs of shoes in 2010 [2]. In the European Union, footwear consumption increased by 22 per cent from 2002 to 2005 to reach 2.3 billion pairs of shoes [3]. Additionally, the worldwide per capita consumption of footwear has also been considerably increased, from one pair of shoes for every person in the world in 1950 to almost 2.6 pairs of shoes in 2005. However, footwear consumption differs significantly between countries. Although China, owing to its large population, has the highest footwear consumption in the world, the 
Table 1 Per capita footwear consumption in different countries

\begin{tabular}{lccr}
\hline Countries & Population (million inhabitants) & Footwear consumption (1000 pairs) & Footwear consumption per capita/year \\
\hline EU-25 & 456.5 & $2054571^{*}$ & 3.5 \\
Germany & 82.5 & $320800^{\dagger}$ & 3.9 \\
France & 59.6 & $335502^{\dagger}$ & 5.6 \\
UK & 59.3 & $395302^{\dagger}$ & 5.3 \\
Italy & 57.3 & $136202^{\dagger}$ & $74102^{\dagger}$ \\
Spain & 41.5 & $2007899^{\ddagger}$ & 3.3 \\
Netherlands & 16.1 & $2900000^{\S}$ & 4.6 \\
USA & 289 & $490000^{\S}$ & \\
China & 1287.1 & $\mathrm{~N} / \mathrm{A}$ & 2.2 \\
Brazil & 186.0 & $\mathrm{~N} / \mathrm{A}$
\end{tabular}

* http://europa.eu.int/comm/enterprise/footwear/statistics.htm [3].

† Footwear Market Survey, 2004 [4].

‡ttp://www.apparelandfootwear.org/data/shoestats2005.pdf [5].

$\S$ Footwear Markets Predictions, 2003 [6].

United States is the country with the highest per capita shoe consumption, since each inhabitant purchases an average of 6.9 pairs of shoes every year. In Europe, and in the case of the 25 member states of the European Union (including the new member states), the yearly per capita shoe consumption in 2003 was 4.5 pairs of shoes, while in the United Kingdom the average was slightly higher at 5.3 pairs. At the other extreme, in the less developed countries, the per capita shoe consumption is 0.6 pairs for India and 0.5 pairs of shoes for Vietnam (all types of shoe included). Table 1 presents the per capita shoe consumption in a number of different countries.

\section{ENVIRONMENTAL CONCERNS IN THE FOOTWEAR INDUSTRY}

There are a number of environmental concerns linked with the footwear industry. These occur both in the production of raw materials and within footwear manufacturing itself and include the use of hazardous materials and chemicals in shoes, the air and water emissions, and the solid waste generated during the production process. In particular, the use of chromium as a tanning agent, which is highly toxic and a suspected carcinogen, has been a major environmental concern for the footwear industry over the last few decades.

However, the most important environmental challenge that the footwear industry is currently facing is the enormous amount of waste generated at the end-of-life phase, with most shoes being disposed of in landfills. Landfill sites can result in serious environmental pollution of groundwater and rivers, caused by landfill leachate (the liquid produced from the decomposition of waste within the landfill). The landfill restrictions introduced by Article 5 of the EU Landfill Directive are very important, in particular the reduction in the amount of biodegradable waste going to landfill and the prohibition of landfilling for certain waste types [7]. Since 1 June 2005, German and Austrian landfills have only accepted biodegradable municipal waste that has been either incinerated or undergone mechanical and biological treatment. Furthermore, the UK Landfill Allowances and Trading Scheme Regulations (LATS) introduced in 2004 determine the percentage of certain waste types that are regarded as biodegradable municipal waste. These biodegradable materials range from paper, card, and vegetable oils (potentially 100 per cent biodegradable) through to footwear, furniture, and textiles (50 per cent biodegradable) to batteries, glass, and metal waste (0 per cent biodegradable) [8]. This means that certain types of biodegradable material such as leather, natural textiles, natural rubbers, etc., which are extensively used by the footwear industry, will soon be required to be reused or recycled instead of directly disposed of in landfill sites.

\section{CURRENT REUSE AND RECYCLING ACTIVITIES IN THE FOOTWEAR SECTOR}

The footwear industry's response to the increasing problem of post-consumer shoe waste has been negligible. In fact, only one major shoe manufacturer, Nike, has taken measures to manage its waste. Nike's recycling programme 'NikeGO Places' (formerly 'Reuse-A-Shoe') is the only product take-back and recycling scheme currently established by a shoe manufacturer. According to Nike [9], since its inception in 1993, the 'Reuse-A-Shoe' programme has recycled more than 16 million pairs of worn-out and defective athletic shoes in total.

Another form of reuse activity in the footwear sector is the collection and distribution of worn or 


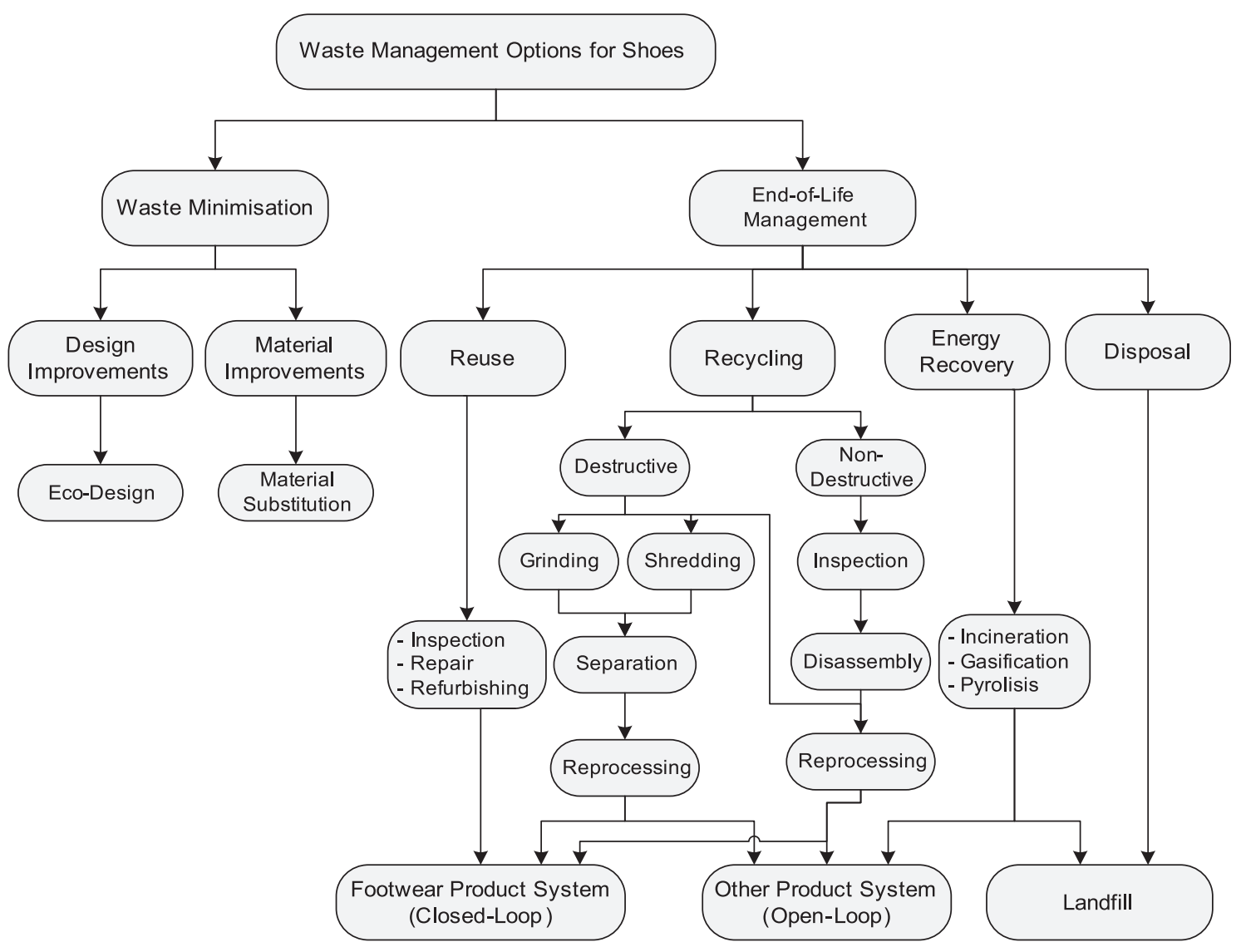

Fig. 1 Waste management framework for shoes

unwanted shoes to developing countries. Reuse schemes are mainly supported by charity organizations, local authorities, and municipalities such as the Salvation Army Trading Company Ltd (SATCOL), Oxfam, and others. However, there is a strong debate about such reuse activities in terms of their overall environmental impact and their economic consequences for local communities. According to Wicks and Bigsten [10], redistribution of secondhand products into developing countries may also lead to net economic damage to the local economies as a result of 'dumping' of cheap used footwear. In the case of Uganda, the import of a large volume of second-hand shoes in recent years has significantly reduced the size of the local footwear industry. About 7 million pairs of second-hand shoes are imported into Uganda annually, while only 240000 pairs are produced by the local footwear industry [11]. However, as the cost of producing new shoes is coming down and the markets are flooded with lower-quality shoes, it is expected that the price difference between new shoes and second-hand shoes will shrink in less developed countries. The demand for second-hand shoes might then drop in these countries, leading to more post-consumer shoes needing to be recycled and disposed of in the developed world.

\section{WASTE MANAGEMENT FRAMEWORK FOR SHOES}

An integrated waste management framework for footwear products has been developed and is presented in Fig. 1. This proposed framework divides the waste management options for shoes into two major approaches: proactive and reactive. Proactive approaches include all measures that are taken with the aim of minimizing waste during both the production and the end-of-life phase. On the other hand, reactive approaches include all the other waste management options which act in response to the waste problem when the useful life of the product has ended, and are hence referred to as end-of-life management.

\subsection{Proactive approaches}

Although there is a wide range of proactive waste management activities, there are two major improvement methods that could be applied in the footwear industry in order to minimize waste at the source, namely design and material improvements.

Design improvements include activities at the beginning of a product's life cycle, i.e. in the product design phase through the application of ecodesign 

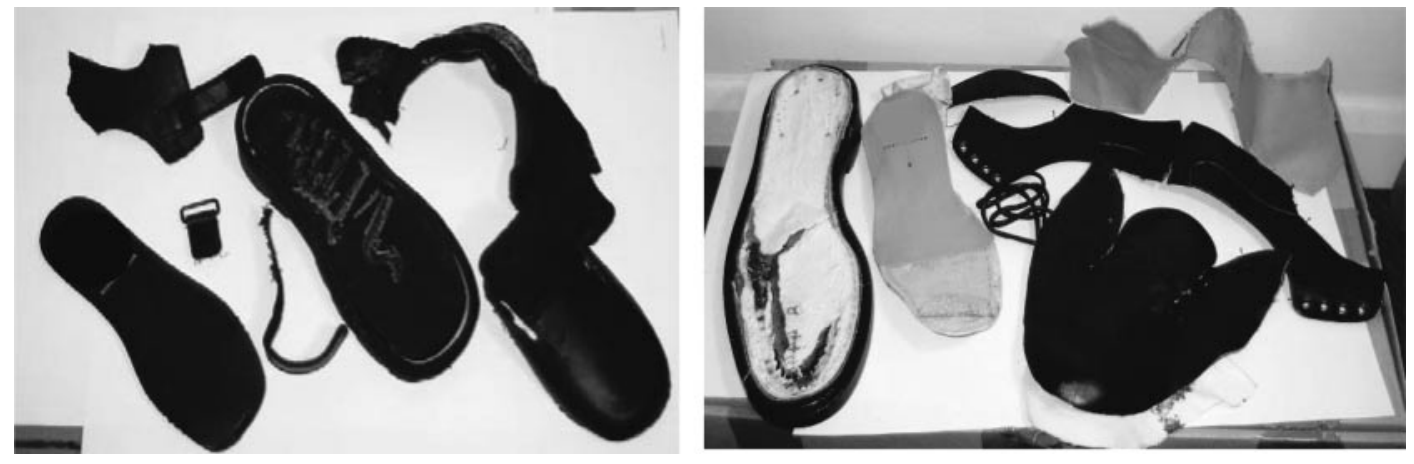

Fig. 2 Disassembly of shoes

concepts. Ecodesign improvements could reduce the amount of materials needed in shoes, thus reducing the amount of waste that needs to be handled at the end of the life cycle.

On the other hand, environmental properties of shoes can also be improved by simply choosing different materials. Material improvements, under certain circumstances, can achieve significant reduction in waste. For example, ecofriendly fabrics can be used in uppers and natural rubber in shoe soles, which can be more easily recycled at the end of the functional life of shoes. Moreover, recycled materials can be used to produce shoes such as Worn Again trainers made from 99 per cent recycled materials such as old tyres, car seat leather, and used coffee bags [12].

\subsection{Reactive approaches (end-of-life management)}

Where waste material is produced, an optimal treatment option must be selected with the lowest possible risks to human health and the environment. Direct reuse of shoes with minimal processing is a possible option, but there are a few variables that need to be considered such as the condition of the shoe at the end of its life, the collection and distribution system, as well as the purpose of its reuse. Recycling involves the reprocessing of end-of-life footwear products, parts, or materials, either into the same product system (closed loop) or into different ones (open loop). The end-of-life waste is therefore reintroduced back into the market through a series of recycling processes that can be divided into two major methods: destructive and nondestructive. Destructive methods, mainly through the shredding process, could be used to transform shoes into other useful materials. Shredded materials can be directly used in secondary applications such as surfacing of roads, playgrounds, and sound insulation. On the other hand, non-destructive recycling methods involve the dismantling of shoes to isolate materials for further recycling in order to obtain a high grade of quality of recycled materials that can be used in a wider range of applications. Non-destructive methods generally include sorting, inspection, disassembly, and then shredding of separated materials. However, disassembly of shoes is not an easy task owing to the large amount of adhesive typically used to join shoe parts together, along with stitching techniques. A number of disassembly experiments related to different types of shoe have been performed as part of this research work, as depicted in Fig. 2. The development of a semi-automated shoe disassembly system is one of the authors' research goals.

An additional reactive waste management option for post-consumer shoes is to generate heat and electricity through energy recovery. This includes a number of established and emerging technologies such as incineration, gasification, and pyrolysis. In the case of leather waste, gasification technology has been applied for heat generation and chromium recovery. Finally, disposal of waste in landfills is often regarded as the last-resort waste management option with the highest environment impact. However, disposal of post-consumer waste may present difficulties in the future owing to recently introduced legislation that bans landfilling of certain waste streams (see section 3).

\section{CHALLENGES IN ESTABLISHING END-OF-LIFE PRODUCT RECOVERY IN THE FOOTWEAR INDUSTRY}

Forthcoming legislation and market pressures are expected to force the footwear industry towards measures to deal with its end-of-life waste. Hence, the authors argue that an end-of-life product recovery system for post-consumer shoes needs to be established to minimize the environmental impacts of end-of-life shoes while taking advantage of the economic value of end-of-life materials, components, and products. This highlights a number of 
challenges for developing such a product recovery chain for post-consumer shoes, which are discussed in the following sections.

\subsection{Establishing sustainable reverse logistics in the footwear sector}

Reverse logistics and collection of post-consumer shoes are already happening, but on a very small scale and mainly for reuse purposes. The standard shoe collection process includes a number of specially designed 'shoe banks' based at recycling stations, schools, charity shops, and other participating outlets. Other possible shoe collection options include kerbside collection (as part of already existing door-to-door municipal waste collection) and recycling point collection systems (where consumers bring all kinds of shoe to containers located in recycling stations). However, at present the lack of an appropriate infrastructure results in a small proportion of post-consumer shoes being collected for recycling, while the majority end up in the normal waste stream for landfill or incineration. Financial incentives could also be considered as an option to facilitate the collection of a greater volume of postconsumer shoes, i.e. a discount on new shoes when you bring back a pair of used shoes. Clearly, establishing sustainable reverse logistics in the footwear industry is one of the key drivers for successful end-of-life product recovery.

\subsection{New generation of recycling processes in the footwear industry}

The consideration of shoe composition clearly indicates that a pair of shoes may contain various recycled materials such as leather (chromium tanned or chromium free), polymers (PU, PVC, etc.) as well as natural and synthetic textiles. The challenge is, therefore, to develop a new generation of recycling processes that provides the technical feasibility to recycle the majority of these materials (either as a raw material, a chemical feedstock, or as energy) in an environmental friendly manner (low emissions and less use of non-renewable energy and other natural resources). The cost of such an environmentally friendly approach to shoe recycling may be higher than the cost of the present waste management method (landfilling) but could become competitive in the longer term as new market opportunities develop for recyclable materials.

The first step in developing a shoe recycling process is successfully to separate post-consumer shoes into well-defined monofraction material streams, which could be based on either mechanical or chemical processes. The research is also exploring the use of such materials in low-grade applications, i.e. equestrian surfacing for horseriding arenas, sound insulation, etc., and possible use in shoe manufacturing.

\subsection{Establishing a value recovery chain for post-consumer shoes}

Once end-of-life shoe waste is collected, separated, and converted into a form that can be used either by the footwear industry or by other industrial sectors, it must compete with virgin materials both on price and performance. A sustainable footwear recycling application depends heavily on establishing a successful value recovery chain. Issues that need to be considered include the size and the value of the end market, the current and predicted buying trends, as well as the range and price of competing materials and products. Furthermore, possible legislative requirements can play an important role in developing economically feasible value recovery chains for post-consumer shoes. Such legislation can take the form of business-centred legislation, i.e. the recycling fee imposed by the car industry and the white goods sector in certain European countries, or consumercentred legislations, i.e. the introduction of a recycling fee for newly sold shoes. The revenues created through such legislation can be used to develop and sustain successful end-of-life product recovery for post-consumer shoes.

\section{CONCLUSIONS}

The large amount of post-consumer shoe waste produced every year, the legislative pressures to divert waste from landfills, as well as the hidden value of recyclable materials in post-consumer shoes have led to the investigation of post-consumer waste management issues in the footwear industry. Past experience in other industrial sectors, i.e. automotive and electrical/electronic equipment, has shown that end-of-life product recovery procedures need to be not only environmentally acceptable but also economically and technologically justified.

Many of the technical, economical, and environmental issues raised in this paper have highlighted the need to overcome the barriers that exist in establishing end-of-life recovery procedures in the footwear industry. Collection of post-consumer shoes, separation into well-defined material streams, and, finally, value recovery of recyclable materials are among the crucial factors in establishing sustainable end-of-life product recovery in the footwear industry. The next phase of the research is exploring these crucial factors to ensure that shoe recovery and recycling is commonplace across the globe in the near future. 


\section{REFERENCES}

1 Soling for low cost footwear. World Footwear, July/August 2006, pp. 18-20 (Shoe Trades, Cambridge, Massachusetts).

2 The future of polyurethane soling. World Footwear, January/February 2005, pp. 18-20 (Shoe Trades, Cambridge, Massachusetts).

3 European Footwear Statistics, 2005, http://europa. eu.int/comm/enterprise/footwear/statistics.htm [4 August 2006].

4 EU market survey 2004: footwear, Centre for the Promotion of Imports form Developing Countries (CBI), December 2004.

5 US Shoe Stats, http://www.apparelandfootwear. org/data/shoestats2005.pdf, 2005.

6 Footwear market predictions: forecasts for global footwear trading to 2009, SATRA Technology Centre, 2003.
7 Council Directive 99/31/EC on the Landfill of Waste, OJ L 182, 26 April 1999.

8 Landfill Allowances and Trading Scheme (England) Regulations, Statutory Instrument 2004 Number 3212, Department of Environment, Food, and Rural Affairs, 2004.

9 NIKE Reuse-A-Shoe, http:/ / www.nike.com [4 August 2006].

10 Wicks, R. and Bigsten, A. Used clothes as development aid: the political economy of rags, http://ideas.repec. org/p/hhs/gunwpe/0017.html, 1996.

11 Temsch, R. and Marchich, M. UNIDO programs funded by Austria to strengthen the leather sector in Uganda, Evaluation report UNIDO projects US/UGA/ 92/200, US/UGA/96/300, United Nations Industrial Development Organisation, http://www.unido.org/ file-storage/download/?file_id $=42858,2002$.

12 Worn Again shoes, http://www.antiapathy.org/ wornagain/home.html [4 August 2006]. 